\title{
Correction to: The Association Between Depression, Suicidal Ideation and Psychological Strains in College Students: A Cross-National Study
}

\author{
Sibo Zhao ${ }^{1}$ (1) Jie Zhang ${ }^{1,2}$
}

\section{Correction to: Cult Med Psychiatry https://doi.org/10.1007/s11013-018-9591-x}

The original version of the article unfortunately contained an error in acknowledgement section. The corrected acknowledgement is: This research was supported by a grant of Beijing Natural Science Foundation (9174046), for which the first author is PI.

The original article can be found online at https://doi.org/10.1007/s11013-018-9591-x.

Sibo Zhao

sibozhao@cufe.edu.cn

Jie Zhang

zhangj@buffalostate.edu

1 School of Sociology and Psychology, Central University of Finance and Economics,

Beijing 100081, China

2 Department of Sociology, Buffalo State College, State University of New York, Buffalo, NY 14222, USA 